\title{
Office of Technology Assessment Report on Tuberculosis
}

Based on a workshop on policy issues in the control of tuberculosis, March 23, 1993, the Office of Technology Assessment (OTA) has published a well-documented, 150-page book entitled The Continuing Challenge of Tuberculosis. This paperback is available for $\$ 9.50$ from the superintendent of documents as S/N 052-003-01341-O c/o PO Box 371954, Pittsburgh, PA 15250-7954. Since OTA is an analytic arm of the Congress, the text first discusses policy options for our government in TB and MDRTB prevention and treatment. It proceeds to review the epidemiology of TB and specific strategies for prevention, treatment, and the delivery of treatment. It concludes with a summary of federal involvement in TB control and research and lists 391 references. Telephone orders are available at (202) 783-3238.

\section{Agency for Health Care Policy and Research Clinical Practice Guidelines}

The Agency for Health Care Policy and Research (AHCPR) listed its current intentions for guideline development in the Federal Register of September 22, 1993. Infectious diseases-related topics currently under development by AHCPR include: 1) Evaluation and Management of Early HIV infection and 2) Otitis Media with Effusion in Children.

The criteria that the agency uses for these guidelines include: 1) amenability of a particular condition to prevention; 2) po- tential for reducing clinically significant variations in the prevention, diagnosis, management, or outcomes of the condition; 3) adequacy of scientific evidence on which to base a guideline; 4) number of individuals affected by the condition; 5) cost of condition to all payers including patients; and 6) specific needs of the Medicare and Medicaid populations.

Based on these criteria, the agency has announced that it is considering the development of guidelines in a number of infectious diseases-related areas including: 1) bacteremia; 2) antibiotic therapy; 3 ) management of surgical wound infections; and 4) community-acquired pneumonia.

AHCPR has extensive information on critical guideline development in a document by that name, dated August 1993, and available from their publications clearinghouse; telephone (800) 358-9295.

\section{Job Market: Opening for Hospital Epidemiologist}

There is a job opening for a hospital epidemiologist at the University of Tennessee, Memphis. The person who fills this position would be a member of the Division of Infectious Diseases in the Department of Medicine and hospital epidemiologist at the Regional Medical Center at Memphis. The hospital epidemiology unit is located in contiguous space at the Regional Medical Center. Resources are available to operate a comprehensive hospital epidemiology program.

The Regional Medical Center is affiliated with the
University of Tennessee and has about 500 beds. The hospital has a level 1 trauma center, a burn center, a large level 3 neonatal intensive care unit, a high-risk obstetrics program, and several medical and surgical intensive care units. Persons interested in this position should write to James B. Dale, MD; Division of
Infectious Diseases; University of Tennessee, Memphis; 956 Court Avenue, Room H-308; Memphis, TN 38163; Telephone (901) 528-5770, FAX (901) 528-5854.

The University of Tennessee is an equal employment/ affirmative action/TitleIX/Section 504/ADA employer.

Brief items of interest for the SHEA N ews or N ewsletter may be sent to C. Glen Mayhall, M D, SHEA, N ewsletter Editor, Division of Infectious Diseases, Route 1092; The Former Shriner's Burns Bldg, Room 2-64B; U niversity of Texas M edical Branch; Galveston, $T X$, 77555-1092; FM (409) 772-6527. Copy should be typed, double-spaced, and should not exceed five pages. 